\title{
REVISÃO BIBLIOGRÁFICA SOBRE EDUCAÇÃO EM SAÚDE PARA OS JOVENS
}

\author{
Sonia Cristina Soares Dias Vermelho* \\ Marina Maldonado Marins Souza**
}

RESUMO: Este artigo apresenta resultado de pesquisa bibliográfica com o objetivo de compreender como a educação em saúde com os jovens vem sendo abordada no Brasil. Selecionamos artigos de congressos e de portais de periódicos. Analisamos 77 artigos pelos resumos e, daqueles que abordavam os jovens, foram lidos na íntegra. O perfil da produção é de pesquisas com foco nas instituições escolares, com predominância nos alunos, mas com uma abordagem mais atrelada a uma concepção de educação mais tradicional. Naqueles artigos específicos sobre jovens, os resultados mostraram que a área de educação em saúde ainda não conseguiu avançar para uma abordagem mais reflexiva e voltada aos problemas mais amplos da sociedade e da juventude, permanecendo ainda numa vertente comportamentalista.

PALAVRAS-CHAVE: Educação em saúde; Juventude; Educação básica

\section{BIBLIOGRAPHICAL REVIEW ON HEALTH EDUCATION TO YOUNG PEOPLE}

\begin{abstract}
A bibliographic research is forwarded on the manner health education is presented in Brazil. Abstracts of seventy-seven articles selected from papers in scientific congresses and journal sites were analyzed. Articles on young people were read fully. Production profile consisted of research work focused on schools, especially on students, with an approach linked to traditional teaching. The articles dealing specifically with young people revealed that health education failed to advance towards a more reflexive approach with a focus on broader issues on society and young people. The behavioral aspect remains prominent.
\end{abstract}

KEY WORDS: Health education; Young people; Basic education.

\footnotetext{
Docente na Universidade Federal do Rio de Janeiro (UFRJ), Rio de Janeiro, Brasil; E-mail: cristina.vermelho@gmail.com

* Mestre Programa de Pós-graduação em Educação em Ciências e Saúde Universidade Federal do Rio de Janeiro (UFRJ), Rio de Janeiro, Brasil.
} 


\section{INTRODUÇÃO}

Este artigo traz o resultado de pesquisa realizada entre os anos de $2015 \mathrm{e}$ 2016 acerca da produção bibliográfica sobre o tema educação em saúde, com recorte para aqueles que tratavam ou dos jovens ou da educação básica. Este tema assume relevância pelo fato de que, historicamente, o termo educação em saúde passou por diversas configurações, as quais representaram interpretações distintas quanto à área de atuação, à orientação teórica metodológica e aos agentes do processo.

A partir da metade do século XIX sob a rubrica da educação higiênica, a área passou nas primeiras décadas do século $\mathrm{XX}$ a ser denominada de educação sanitária. A escola não seria apenas um espaço de ensino, mas também seria capaz de corrigir, por meio da higiene, a saúde da criança e do adolescente (MOHR; SCHALL, 1992). Nesta perspectiva, a saúde individual era vista como a base da estabilidade da população, sem considerar as questões sociais e processo histórico de sua origem e manutenção (LOUREIRO, 1989).

Desde os anos 1950 até o início dos anos 2000, passando pela redemocratização do Brasil e pela Constituição Federal de 1988, muitas iniciativas e abordagens com uma perspectiva sanitária foram realizadas no espaço escolar com os estudantes, tendo como ações, os cuidados de higiene e primeiros socorros. Ou seja, ações curativas e "medicalizadas", as quais deveriam solucionar os problemas ligados à capacidade de aprender (BRASIL, 2009).

Contudo, ainda nos anos de 1960, sob forte centralização administrativa da política nacional de saúde, surgem outros modos de entender o estreitamento entre educação em saúde. A abordagem sanitária deixa de ser a única opção para trabalhar a articulação entre educação em saúde. Alternativas têm como princípio norteador um conceito ampliado de saúde, com foco na integralidade e na produção de cidadania e da autonomia e que promova uma participação maior da comunidade nos processos de educação em saúde. Esta vertente teve forte influência das ideias de Paulo Freire, contudo não representou o contexto geral do país (MOHR; SCHALL, 1992; VENTURI; MOHR, 2011).

No campo da saúde, com a Conferência de Alma-Ata em 1978, os órgãos internacionais de saúde, como a Organização Mundial de Saúde (OMS), passaram 
a se preocupar com a necessidade de inserir o contexto cultural das populações para adequar melhor as práticas de saúde. Além disso, na década de 1980, a crítica do setor de educação em relação ao setor de saúde foi de que este não utilizava a escola como aliada e parceira. A educação para a saúde, baseada no modelo médico tradicional e focalizada no controle e na prevenção de doenças, é pouco efetiva para estabelecer mudanças de atitudes e opções mais saudáveis de vida que minimizem as situações de risco à saúde de crianças, adolescentes e jovens adultos. Porém, as prioridades continuaram sendo determinadas sem se deixar questionar os interesses e saberes da população (VASCONCELOS, 2001).

No Brasil tivemos a promulgação da lei 5.962/71, em que é inserida a educação em saúde como atividade obrigatória nos currículos de primeiro e segundo graus. Essa lei é promulgada em pleno regime militar ditatorial, tinha como propósito adequar a educação às determinações econômicas da época. $\mathrm{O}$ novo modelo educacional inseriu em seu ordenamento jurídico a Teoria do Capital Humano (TCH) que deu apoio ao discurso economicista das políticas do capital internacional (FRIGOTTO, 1999). Neste cenário, o discurso liberal impôs uma tendência tecnicista como referencial para a organização da educação brasileira dando ênfase na eficiência técnica do sistema, na maximização dos resultados, nos meios e nas técnicas educacionais, portanto, na dimensão quantitativa do sistema (FICO, 2004).

Esta concepção esteve presente nas políticas educacionais até as décadas de 1980 e 1990. Contudo, na última década do século XX, sob gerência dos organismos internacionais, foi implementada uma política educacional de descentralização e desconcentração com ênfase na autonomia das instituições educacionais. No final dos anos 1980, no bojo do processo de redemocratização, a educação passa a ter forte crítica da Pedagogia Libertadora (Paulo Freire) cuja ênfase na dimensão política da educação era bastante grande.

Os pensamentos de Paulo Freire, referentes à pedagogia libertadora, tem como princípio, uma educação baseada na construção dos conhecimentos e na criação de uma sociedade mais justa. Ele defende que a educação deve estar ao lado das classes oprimidas, pela luta ao direito da liberdade e igualdade. Para isso, é fundamental entender que tanto o aluno quanto o educador, devem dialogar entre 
si, pois ambos ensinam e aprendem nos espaços de construção do conhecimento. Como já dizia Paulo Freire, "ninguém educa ninguém, ninguém educa a si mesmo, os homens se educam entre si, mediatizados pelo mundo" (FREIRE, 1970, p. 39).

Contudo, o campo da educação em saúde em sua vertente mais tradicional esteve atrelado à ideia do controle do modo de vida das pessoas pelo Estado, no sentido de adaptar os indivíduos à ordem social vigente. Neste sentido, são discursos e práticas autoritárias do Estado para a sociedade ditando normas de conduta com a finalidade de garantir a melhoria da qualidade de vida. De acordo com estas concepções, a finalidade do trabalho dos profissionais de saúde, como "detentores do saber científico", seria fornecer orientações, instruir sobre autocuidado para a prevenção de doenças e demonstrar técnicas de higiene para criação de hábitos saudáveis, caracterizando o que denominamos de uma concepção de educação em saúde numa abordagem tradicional-diretiva.

Podemos dizer que, ainda hoje, a vertente mais tradicional do campo da educação em saúde continua repetindo o modelo da "Educação Bancária" criticado por Freire, "[...] o educador é o sujeito, conduz os educandos à memorização mecânica do conteúdo narrado. [...] não há criatividade, não há transformação, não há saber" (FREIRE, 1987, p.33).

Neste cenário da educação dita tradicional, o saber popular não é tido como um conhecimento relevante capaz de solucionar problemas de saúde, pois a cultura popular é desvalorizada e negada pela hegemonia do saber científico. Entretanto, os estilos e modos de vida não podem ser compreendidos de forma isolada como se os sujeitos fossem independentes do ambiente e das relações sociais determinadas pela cultura onde vivem. Esta individualização é uma abstração conceitual fragmentada que termina por difundir a ideia de que os sujeitos são os únicos culpados pela sua situação de saúde, desconsiderando as relações sociais de produção que determinam socialmente a vida dos indivíduos.

Nas últimas décadas, o campo da promoção da saúde tem tentado promover ações em que o contexto e o saber popular sejam considerados nas práticas educacionais e de saúde, visto que consideram a saúde, como um processo de transformação social e não como um processo individualizado e fragmentado, que coloca os sujeitos como os únicos responsáveis pelas mudanças ocorridas no processo saúde-adoecimento ao longo da vida (MELO, 2007). 
No Brasil, foi imprescindível para a difusão desta concepção ampliada de educação em saúde, a ação política do movimento da reforma sanitária que teve seu apogeu na VIII Conferência Nacional de Saúde (CNS). Na Constituição Federal de 1988. Na Constituição a saúde é definida como um direito social de todos os cidadãos e um dever do Estado brasileiro, criando o amparo legal para o Sistema Único de Saúde (SUS) que tem como princípios doutrinários a universalidade, a equidade e a integralidade.

Em função desse cenário, penso que é de extrema importância considerar o caminho da prática por meio de uma proposta de educação em saúde participativa dos sujeitos envolvidos, na qual o conhecimento seja construído e não imposto por medidas tomadas por instâncias superiores. É necessária uma troca de conhecimentos e experiências, trabalhadas dialeticamente, não invalidando o saber técnico, nem subestimando o saber popular, um processo que se apoia das concepções e na filosofia de Freire (1970 e 1997). Denominamos esta concepção de educação em saúde de crítico-reflexiva.

As diretrizes da educação para a saúde ainda definem educação em saúde como "[...] uma atividade planejada que objetiva criar condições para produzir as mudanças de comportamento desejadas em relação à saúde" (MINISTÉRIO DA SAÚDE, 1980 apud GAZZINELLI et al., 2005, p. 201), o que significa que os projetos de educação para a saúde ainda tratam o público como objeto de transformação (GAZZINELLI et al., 2005). As práticas e discursos normativos, conteudista e cientificista não necessariamente resultam em mudança de comportamento. Defendemos que se deve pensar em educação em saúde que leve em conta as representações dos sujeitos, influenciados pela experiência coletiva e admitir que elas e outros tipos de saberes devam estar presentes nos espaços de ensino. Leva-se em consideração aqui que a educação em saúde se torna uma "construção compartilhada de conhecimento" (GAZZINELLI et al., 2005. p. 101).

Refletir sobre educação em saúde implica na observação de inúmeros aspectos. Dentre eles podemos destacar, na articulação da educação escolar com a área da promoção da saúde, a necessidade de implantação de uma política mais transversal, que sugere a articulação entre os serviços de saúde, a comunidade, às iniciativas pública e privada, além do próprio cidadão nas ações que busquem bemestar e qualidade de vida (BRASIL, 2006). 
Contudo, é necessário compreender os fatores que determinam os estilos de vida da sociedade. Segundo alguns autores, esses estilos estão relacionados com uma complexa interação de fatores biológicos, psicológicos, micro e macrossociais, além dos fatores ambientais (GOMES, 2009, p. 85). Por este motivo, a escola é um dos meios que pode contribuir para promover não só a mudança de hábitos, mas um pensamento crítico a respeito da saúde tanto individual quanto coletiva, promovendo uma educação que estimule o agir como sujeitos de suas próprias vidas (STOTZ, 1993).

Neste trabalho, tomamos como referência o posicionamento teórico e prático que entende que as ações de educação em saúde devem estar atreladas às relações sociais, entendendo todos os sujeitos como atuantes dos processos para melhoria das suas condições de saúde e de toda a comunidade.

\subsection{EDUCAÇÃO EM SAÚDE NAS ESCOLAS}

A escola é um dos alicerces não só da educação, mas da cidadania. É por meio dela que a criança inicia sua educação, sua integração e inclusão social, ou seja, nas relações que se estendem ao longo da vida (LIBERAL, 2005).

Segundo Costa et al. (2008), é de extrema importância a valorização das relações entre professor, profissional de saúde e comunidade, para que todos possam participar no processo de transformação dos sujeitos e da melhoria de suas condições de saúde. Diante disso, percebe-se que educação em saúde, como promoção da saúde no ambiente escolar, ocorre por meio da construção de parcerias e do abandonando do antigo modelo educacional, que estaria centrado apenas na figura do professor, sendo ele o detentor de todo o saber (COSTA et al., 2008).

Porém, como também observou Gomes (2009), a criação de uma escola promotora de saúde não é um processo fácil, pois há fraca participação do setor da saúde, há ausência de cursos de formação para professores nesta área, aliada à falta de tempo dos professores para planejarem projetos, além do pouco envolvimento dos pais nas tomadas de decisão da escola.

Pensamos que diante dessas dificuldades, seja importante um método de ensino baseado em uma relação dialógica entre os atores da aprendizagem, 
conforme propôs Freire (2001), em que seja privilegiado o diálogo para que aconteça a verdadeira comunicação, onde os interlocutores são ativos e iguais. Talvez esse seja um dos caminhos para superar as dificuldades de promover uma educação em saúde crítica e reflexiva. Aprender é um ato de conhecimento da realidade concreta, isto é, da situação real vivida pelo educando, que se dá por meio de uma aproximação crítica dessa realidade. O que é aprendido não decorre da imposição ou memorização, mas do nível crítico de conhecimento ao qual se chega pelo processo de compreensão, reflexão e crítica (LIBÂNEO, 1983).

Ou seja, a escola é um espaço privilegiado no desenvolvimento do pensamento crítico e político dos jovens, à medida que contribui na construção de valores, crenças, conceitos e maneiras de conhecer o mundo, o que interfere diretamente na produção social da saúde.

De acordo com o PSE:

A Saúde, como produção social, exige a participação ativa de todos os sujeitos na construção de ações que visam às escolhas mais saudáveis. Dar visibilidade aos fatores que colocam a saúde em risco e desenvolver estratégias para superar os problemas e as adversidades identificados e vivenciados pela comunidade são propostas de ações em Saúde. (BRASIL, 2015, p.20)

No início dos anos 1990, diante das propostas do setor de educação, da crescente crítica em relação a pouca efetividade da educação em saúde nas escolas e do fortalecimento das políticas de promoção da saúde, o Ministério da Saúde recomendou a criação de espaços e ambientes saudáveis nas escolas, com o objetivo de integrar as ações de saúde na comunidade educativa (BRASIL, 2006). Como preconiza o PSE (2015),

Nas escolas, o trabalho de promoção da saúde com os estudantes, e também com professores e funcionários, precisa ter como ponto de partida "o que eles sabem" e "o que eles podem fazer". É preciso desenvolver, em cada um a capacidade de interpretar o cotidiano e atuar de modo a incorporar atitudes e/ou comportamentos adequados para a melhoria da qualidade de vida. (BRASIL, 2015, p. 8)

Nesse processo de melhoria da qualidade de vida da população, as bases são as "forças" de cada um, no desenvolvimento da autonomia e de competências 
para o exercício pleno da cidadania. Assim, dos profissionais de saúde e de educação espera-se que, no desempenho das suas funções, assumam uma atitude permanente de empoderamento dos estudantes, professores e funcionários das escolas, é o princípio básico da promoção da saúde (BRASIL, 2009).

A Organização Mundial de Saúde (OMS) define que "a promoção da saúde é um processo que objetiva ampliar as possibilidades dos cidadãos de controlar, de forma crescente, os determinantes sociais de saúde e, como consequência, melhorar sua qualidade de vida" (BRASIL, 2015) Sendo assim, uma das linhas de atuação da promoção de saúde é construir ações educacionais que visam garantir oportunidades a todos os educandos a fazerem escolhas mais favoráveis à saúde e de serem, portanto, protagonistas do processo de produção da própria saúde.

Neste contexto, a escola, juntamente com outros espaços sociais, tem como objetivo primordial desenvolver processos de ensino-aprendizagem, onde cumprem papéis decisivos na formação dos estudantes e na construção da cidadania e no acesso às políticas públicas (BRASIL, 2009). Desse modo, visto que a escola é um espaço importante para a saúde e prevenção de agravos à saúde, o PSE visa "proporcionar à comunidade escolar a participação em programas e projetos que articulem saúde e educação" (BRASIL, 2015, p.7).

O PSE, criado pelo trabalho integrado entre os Ministérios da Saúde e o da Educação, e instituído em 05 de dezembro de 2007 pelo decreto presidencial nº 6 . 286, diz que, "ter saúde é reunir condições de estudar adequadamente, conviver e socializar. Com isso, para ter saúde, precisamos de ambientes saudáveis, alimentação adequada e equilíbrio emocional e físico". (BRASIL, 2015, p.22). Neste contexto, as áreas de educação em saúde estão interligadas, visto que "bons níveis de educação estão relacionados a uma população mais saudável assim como uma população saudável tem maiores possibilidades de apoderar-se de conhecimentos da educação formal e informal" (CASEMIRO; FONSECA; SECCO, 2014, p. 830).

Contudo, segundo Casemiro, Fonseca e Secco (2014, p. 830), a América Latina é marcada por desigualdades históricas. Houve aumento na universalização do acesso ao ensino fundamental, porém, os baixos investimentos dos governos se mantiveram, o que resulta em condições precárias de salário, trabalho e de escolas com qualidade para todos. Sendo assim, é de grande importância estudar e debater 
questões sobre desigualdades e má condições, tanto dos sistemas educacionais quanto dos sistemas de saúde para recuperar o sentido social e cultural da educação, na perspectiva de que esta se torne "mais justa e igualitária, mais democrática e participativa" em toda a América Latina".

Acreditamos que a questão não seja culpabilizar o indivíduo e a população pelas suas más condições de vida e de atitudes relacionadas à saúde. Devemos considerar o contexto local, ou seja, as suas condições de moradia, alimentação, educação, entre outros. Devemos identificar problemas reais e traçar estratégias e soluções viáveis para enfrentar estas problemáticas, "[...] de forma a contribuir para a autonomia e o apoderamento dos sujeitos diante dos direitos fundamentais relacionados ao tema da saúde escolar: direito à saúde, à educação, à alimentação e à vida digna" (CASEMIRO; FONSECA; SECCO, 2014, p. 839).

\subsection{EDUCAÇÃO EM SAÚDE COM JOVENS}

As escolas situadas em um território vulnerável e com um público em situação de vulnerabilidade social precisam da implementação de propostas educativas no campo educacional que vise promover a reflexão e a formação para a cidadania. Acredito que o contexto determina em grande medida a operacionalização das políticas para os jovens e situação de vulnerabilidade social (AABRAMOVAY, 2004; SPOSITO, 2009). Carrano e Martins (2011, p. 8) afirma que é fundamental que as instituições contribuam "[...] para que os jovens possam realizar escolhas conscientes sobre suas trajetórias pessoais e constituir os seus próprios acervos de valores e conhecimentos que já não mais são impostos como heranças familiares ou institucionais."

Os desafios dos jovens brasileiros que se encontram em situação de vulnerabilidade social são enormes; envolvem não somente a educação, mas também outros setores sociais. Considera-se que a educação tem um papel a cumprir para o futuro dessa juventude, na qual se deve promover experiências formativas emancipadoras para um público em que as condições econômicas, sociais, culturais e ambientais onde vivem os incluem no conceito de vulnerabilidade social (FÁVERO et al, 2007; CARRANO, 2011). 
Desde a primeira metade do século XX, a juventude passou a ocupar lugar na sociedade (SAVAGE, 2009), as marcas desse processo, mostra que [...] o significado da categoria juventude é relacionado a outras dimensões da vida social. No entanto, não se pode esquecer que as categorias não são neutras, e que tem relação com as diversas maneiras que as sociedades percebem e valorizam certos atores sociais (CASTRO, 2014, p. 27).

No Brasil, a crescente urbanização trouxe uma série de problemas relacionados aos jovens, em particular aqueles relacionados à prática da criminalidade (ADORNO, 1991). Infelizmente a sociedade brasileira apresenta assimetrias nos acessos aos bens públicos. É neste cenário que parte da juventude brasileira vem se constituindo enquanto sujeitos, num processo de socialização em que a escola assume papel sobre o qual devemos problematizar.

Vale ressaltar os constantes relatos de violência no interior da escola com professores, com o patrimônio público, com práticas de violência de gênero, de etnia etc. A instituição social privilegiada para atuar na formação das novas gerações vê-se em meio a constantes críticas por parte da sociedade, mas também daqueles que deveriam ser seus principais defensores: o(a)s aluno(a)s. A escola hoje estaria longe de colaborar para a formação político-cultural, o ser crítico, propositivo e sensível à diversidade e a desigualdades sociais, ou seja, para o exercício da potencialidade do/ da jovem vir a ser sujeito de transformações sociais (CASTRO, 2014, p. 29).

Juventude [...] não é um conceito abstrato, mas uma potencialidade que se realiza por mais diversas performáticas ou que é abortada, deixando cruzes, desencantos, participando de violências, registros de cidadanias negadas. Juventudes na juventude sinalizam buscas por múltiplas cidadanias, pelo direito de reinventar direitos (CASTRO, 2014, p. 38). Historicamente, na sociedade capitalista quando a juventude se tornou um "público-alvo" ganhou também o status de grupo etário com suas especificidades, ganhou direitos e deveres e passou a ter exigências próprias (SAVAGE, 2009), mas também a ser observada dentro de um quadro de problemas de comportamento associada à idade.

Para a sociedade urbana e burguesa da época, era conveniente que a criminalidade estivesse associada a alguma deformação de origem biológica e hereditária, e não em relação com o modo como a sociedade se organizava. No final 
do século XIX, não foi sequer discutido que a origem da criminalidade cometida pelos jovens já estava associada às condições brutais em que eles eram submetidos: pouca escolaridade, trabalho infantil endêmico, uma puberdade em que tinham que lutar arduamente pela sobrevivência, muitas vezes abandonados pelas famílias (SAVAGE, 2009).

Nas populações das favelas do Rio de Janeiro entra-se um problema que está relacionado à saúde do jovem. Segundo Kahhale (2003), a gravidez na adolescência tem sido alvo de estudos e preocupação dos órgãos governamentais ligados à saúde. Certamente esse é encarado como um problema de saúde na atualidade porque a gravidez na adolescência é considerada um fator de risco, pois compromete a inserção social e qualidade de vida da futura mãe e do bebê. Principalmente nas classes mais desfavorecidas economicamente porque, junto com a gravidez vem o abandono da escola, a entrada precoce no mercado de trabalho, entre outras complicações.

Concordo com Gonçalvez (2003) quando ele aborda o quanto é fundamental investigar o desenvolvimento da consciência dos adolescentes considerando todos esses aspectos, numa reflexão crítica dessas mediações presentes em nossa sociedade. O predomínio de determinada representação de adolescência no meio social implica no predomínio de determinados significados sociais relativos a ela. Implica também que o jovem se apropria dessas representações para se constituir enquanto sujeito.

Reconhecer as representações sociais de adolescência predominantes em um meio social nos permite discutir em que medida existe espaço social para uma vivência e significação crítica (GONÇALVEZ, 2003).

Sendo assim, tracei o perfil das pesquisas realizadas na interface da educação em saúde com jovens da educação básica, pois acredito ser de extrema importância entender os trabalhos já realizados neste contexto.

\section{METODOLOGIA}

O desenho do estudo foi bibliométrico de caráter exploratório e descritivo (SILVA; HAYASHI; HAYASHI, 2011; VERMELHO; AREU, 2005; FERREIRA, 2002; 
ANDRÉ; ROMANOWSKI, 2002; ROCHA, 1999; MESSINA, 1998), cuja natureza possibilita a construção de indicadores sobre a produção científica de indivíduos, áreas do conhecimento, países etc. A natureza do material bibliográfico analisado foi de artigos publicados nos Encontros Nacionais de Pesquisa em Educação em Ciências (ENPEC's VIII e IX) e no portal de periódico da Capes.

Quanto aos critérios de inclusão/exclusão foram definidos: trabalhos publicados nos eventos citados, em língua portuguesa, artigo completo, disponível na internet na íntegra. Os dados coletados dos artigos foram: título, autor(es), instituição de vinculação do(s) autor(es), palavras-chave e o resumo. Esses dados foram organizados numa planilha do Excel e posteriormente inseridos no software de análise estatística Sphinx Léxica, versão 5.1. A escolha desse software para apoiar a análise dos artigos foi em função de que o mesmo permite análises quantitativas e qualitativas por meio de análise do conteúdo a partir de categorias analíticas e os testes de hipótese a partir da quantificação das categorias analíticas.

Com base nos estudos anteriores e nos trabalhos de Melo (1992), definimos as seguintes categorias analíticas: Agente; Instituição Pedagógica; Nível de Ensino e Concepção Educacional. Quanto à concepção educacional, tomamos como parâmetro aquela defendida no artigo para classificá-lo como integrante de uma concepção teórica com tendência ao modelo educacional com orientação tradicionaldiretivo, tecnicista-comportamental ou crítico-reflexivo.

A escolha do evento do Enpec deve-se ao fato que de, historicamente, a vinculação da área de educação em saúde e a educação em ciência acontece desde a criação dos programas de saúde na escola, pois tradicionalmente as temáticas da saúde na educação básica se davam nas disciplinas de ciências. Mesmo no contexto mais atual e apesar da transversalidade do tema proposto pelos $\mathrm{PCN}^{\prime} \mathrm{s}$, continua sendo a disciplina de ciências que se responsabiliza pela educação em saúde nas escolas. (VENTURI; MOHR, 2011)

A partir do V ENPEC havia um grupo de trabalho que discutia a educação em saúde, mas foi somente no VIII ENPEC que foi criada a linha temática "Educação em saúde e ensino de ciências", renomeada por "Educação em Saúde e Educação em Ciências" no IX encontro.

Esses dados foram coletados pela análise do resumo do trabalho e consistiu num esforço de compreender a inter-relação das teorias educacionais que impregnam os modelos educacionais e a abordagem dada ao trabalho ou à interpretação do 
contexto analisado. Neste esforço teórico identificamos similaridades de pressupostos dos modelos educacionais com os vários momentos pelo qual passou a educação em saúde: a educação sanitária, na qual identificamos similaridade com a teoria educacional tradicional-diretiva; a educação para a saúde, guardando semelhança com a teoria tecnicista-comportamental e, finalmente, a educação em saúde, a qual possui orientações convergentes com as teorias educacionais crítico-reflexivas.

Após a análise, observamos maior predominância em trabalhos que estavam interessados em estudar os discentes da educação básica, sendo assim, a partir desta análise inicial, foi possível quantificar e qualificar estes trabalhos de forma mais aprofundada (leitura completa dos artigos), a fim de compreender o que já se estudou com jovens na área de educação em saúde.

Neste segundo recorte dos dados, a seleção se deu pelos descritores "juventude", "educação" e "saúde" e mantivemos apenas os artigos que tratavam da juventude com a educação em saúde nas escolas. Aqueles que estavam relacionados com o nosso objetivo foram lidos na íntegra, analisados e descritos quanto ao assunto tratado.

\section{RESULTADOS E DISCUSSÃO}

Inicialmente apresentamos nas tabelas a seguir os dados de perfil dos artigos analisados. Em relação à quantidade apresentada nos dois últimos ENPEC's, podemos afirmar que o aumento foi significativo quando aplicado o teste do Qui2 (Tabela 1).

Tabela 1. Distribuição da frequência dos artigos apresentados e aceitos nos VIII e IX ENPEC

\begin{tabular}{llllll}
\hline ENPEC & Ano & Freq. & \% & Art. aceitos & \% sobre o total de artigos \\
\hline VIII & 2011 & 31 & $40,3 \%$ & 1009 & $3,07 \%$ \\
IX & 2013 & 46 & $59,7 \%$ & 1026 & $4,48 \%$ \\
TOTAL & & 77 & $100 \%$ & 2035 & $3,78 \%$ \\
\hline
\end{tabular}

Fonte: Dados da pesquisa

Em relação ao agente do processo, realizamos categorização a partir da leitura dos resumos (Tabela 2). Importante observar que o total da tabela (52) 
não corresponde ao total de artigos analisados (77) pelo fato de que 25 artigos não tiveram como objeto de investigação pessoas ou grupos. Dentre os 25 não indicados na Tabela 2, encontramos artigos que trataram de revisão de literatura (12), livros didáticos (10), filme (2) e currículo (1). De acordo com nosso referencial teórico, definimos a categoria agente exclusivamente como sujeitos do processo educativo, portanto excluímos os demais para essa análise. O resultado apresentou predominância significativa para os discentes, o que nos permite deduzir que existe uma predominância de trabalhos tendo o aluno (a) como foco.

Tabela 2. Distribuição quanto ao agente abordado no artigo

\begin{tabular}{lll}
\hline Agente & Freq. & $\%$ \\
\hline Discentes & 29 & $37,7 \%$ \\
Docentes & 14 & $18,2 \%$ \\
Profissionais de saúde & 5 & $5,2 \%$ \\
Comunidade escolar & 2 & $2,6 \%$ \\
População & 2 & $2,6 \%$ \\
TOTAL & 52 & \\
\hline
\end{tabular}

Fonte: Dados da pesquisa

Quanto à instituição, como demonstrado na Tabela 3, a predominância foi do espaço formal escolar em todos os níveis. Percebe-se uma influência massiva dos educadores na produção da área e um número muito menor de trabalhos a partir dos espaços da saúde.

Tabela 3. Distribuição quanto a instituição pedagógica abordado no artigo

\begin{tabular}{lll}
\hline Instituição pedagógica & Freq. & $\%$ \\
\hline Formal (escola) & 72 & $93,5 \%$ \\
Formal (unidade de saúde) & 2 & $2,6 \%$ \\
Não formal (educação popular) & 2 & $2,6 \%$ \\
Não formal (espaço comunitário) & 1 & $1,3 \%$ \\
TOTAL & 77 & $100 \%$ \\
\hline
\end{tabular}

Fonte: Dados da pesquisa 
Quanto ao nível, pode-se observar na Tabela 4, predominaram os estudos relacionados à educação básica. Esses aspectos da produção de uma predominância da educação formal no nível básico corroboram os resultados encontrados por Venturi e Mohr (2011) dos anos anteriores dos trabalhos apresentados nos ENPEC's anteriores.

Tabela 4. Distribuição quanto ao nível educacional abordado no artigo

\begin{tabular}{lll}
\hline Nível Educacional & Freq. & $\%$ \\
\hline Educação básica & 47 & $61,0 \%$ \\
Ensino superior & 12 & $15,6 \%$ \\
Não se aplica & 12 & $15,6 \%$ \\
Pós-graduação & 4 & $5,2 \%$ \\
Não identificado & 2 & $2,6 \%$ \\
TOTAL & 77 & $100 \%$ \\
\hline
\end{tabular}

Fonte: Dados da pesquisa

E finalmente, quanto à concepção educacional explicitada e/ou defendida no texto, encontramos na Tabela 5 uma distribuição equitativa entre as três abordagens.

Tabela 5. Distribuição quanto a concepção educacional abordado ou defendida pelo autor

\begin{tabular}{lll}
\hline Concepção educacional & Freq. & $\%$ \\
\hline Tradicional diretiva & 22 & $43,1 \%$ \\
Tecnicista comportamental & 16 & $31,4 \%$ \\
Crítico reflexivo & 13 & $25,5 \%$ \\
TOTAL & 51 & $100 \%$ \\
\hline
\end{tabular}

Fonte: Dados da pesquisa

Contudo se agruparmos as tendências mais tradicionais (tecnicista comportamental + tradicional diretiva), podemos afirmar que existe uma predominância de enfoques mais identificados com os modelos pedagógicos dos anos 1970 e 1980, em que a ênfase do processo educacional esteve pautado na 
teoria do capital humano e no comportamentalismo. Essa característica foi discutida por Adriana Mohr em sua tese de doutoramento em que identificou que nas escolas a educação em saúde, apesar das mudanças nas orientações (nos documentos, nas discussões teóricas etc) para tornar-se um processo mais amplo, dinâmico e com cunho sociocultural, ambiental e econômico, os enfoques nas escolas continuavam "[...] ultrapassados e inadequados, com ênfase em objetivos comportamentalistas e sanitaristas, inadequados em uma situação de educação escolar." (VENTURI; MOHR, 2011, p. 4).

Dos 77 trabalhos encontrados nos ENPC's VIII e IX, 27 estavam relacionados com pesquisas feitas com discentes, 18 foram utilizados para análises mais aprofundadas, visto que delimitamos não só os artigos que tratam dos discentes, mas que também aqueles que estavam relacionados com a educação básica e juventude. São eles: Carvalho e Gonçalves (2011), Marinho e Silva (2013), Costa e Zancul (2013), Lanes et al. (2011), Lanes et al. (2013), Fagundes e Pinheiro (2013), Santos e Oliveira (2013), Menezes e Chaves (2013), Perim et al. (2013), Nunes et al. (2011), Costa e Zancul (2013), Silva, Severo e Dias (2011), Ramos e Fagundes (2011), Ilha et al. (2013), Monteiro, Vargas e Rebello (2003), Blasca et al. (2013) e Beserra et al. (2011) e Talamoni e Filho (2011).

Destes trabalhos analisados, observamos que as questões de saúde dos jovens na educação básica foram todos empíricos e que poucos estão relacionando a saúde como uma questão crítica e reflexiva, mas como uma questão mais diretiva, tecnicista e comportamental, corroborando a análise feita preliminarmente. Poucos são os trabalhos que colocam a necessidade de trazer o contexto social e a reflexão para o centro do processo.

Trabalhos como o de Costa e Zancul (2013), na qual ao concordarem com Alves (2005), acreditam que:

[...] a educação em saúde pode ser caracterizada como um campo do saber no qual o conhecimento produzido nas áreas de saúde e educação instrumentalizam os indivíduos de uma sociedade para a adoção de novos hábitos e condutas que garantam a aquisição e manutenção de seu estado de saúde. (ALVEZ, 2005, p.2)

Lanes et al. (2011) pesquisaram sobre a obesidade dos jovens escolares; os autores acreditam que os seu estilo de vida e hábitos podem ser moldados e iniciam 
em fases precoces da vida. Sendo assim, as intervenções devem ser realizadas na infância e na adolescência, a fim de evitar condutas desfavoráveis ao decorrer do seu crescimento e desenvolvimento. Eles concluem que se deve "intervir nas várias esferas da vida das pessoas no sentido de promover a adoção de comportamentos saudáveis" por meio da educação para a saúde (p. 10).

O mesmo pode se observar no trabalho de Lenes et al. (2013), onde informam que "as escolas precisam incorporar de forma precoce temas como saúde para que os indivíduos tenham instrução necessária a fim de prevenir doenças e de promover a saúde" (p.7).

Costa e Zancul (2013) acreditam ser necessário que os estudantes possam constatar que os diversos sons em intensidade acima do recomendado possa trazer malefícios fisiológicos ao decorrer de suas vidas. Desta forma, seu artigo apresenta quais níveis de decibéis os estudantes estão ouvindo músicas para então orientálos, ou seja, trata-se de uma abordagem descontextualizada, sem dialogar com a dinâmica da juventude na atualidade.

Silva, Hayashi e Hayashi (2011) também afirmam que precisamos operar por meio de uma educação voltada para a saúde para suprir a carência de informações e conhecimentos. Eles acreditam que "esta forma de pensar o ensino preocupa-se, também, em contribuir com a consequente mudança de hábitos que sejam danosos à sanidade da população" (p.2). Acreditam também que os comportamentos se devem à falta de informações e orientações, o que nos parece pouco explicativo para o contexto atual tendo em vista os inúmeros canais de acesso a informações não só na escola como fora dela.

A necessidade de trabalhar temas que estejam relacionados à promoção da saúde também é tratado no trabalho de Ilha (2013, p. 3) acreditam que "a escola torna-se um espaço privilegiado, para influenciar, orientar as atitudes e valores dos estudantes ao longo de toda a sua escolaridade, bem como, conscientizá-los a adoção de hábitos que permitam uma melhor qualidade de vida".

Entendemos que estes autores tratam a escola e a educação em saúde como uma forma de garantir que os estudantes sejam capazes de corrigir, por meio da higiene, mudanças de hábitos, condutas e comportamentos. Os trabalhos não articulam uma ideia de compreensão coletiva dos problemas de saúde e uma 
conscientização crítica dos seus próprios atos; abordam a educação como uma forma de instruir os jovens e não de dialogar com os mesmos.

Somente dois trabalhos apresentaram um viés de educação em saúde mais crítico. No trabalho de Carvalho e Gonçalves (2011), na qual foi mencionado que a escola pode ser capaz:

[...] melhorar as competências cognitivas, psicológicas e sociais dos educandos, promovendo os valores e conduzindo os alunos ao desenvolvimento da sua personalidade, para saberem integrar-se na comunidade a que pertencem e levando-os a assumirem progressivamente as responsabilidades da sua existência. (p. 2)

Além disso, Marinho e Silva (2013) abordam sobre a importância da educação em saúde no âmbito escolar, visto que contribui para a construção e consolidação da cidadania. Sendo assim, estudando as atividades criadas por professores que envolvem essa temática, observaram que muitas se caracterizam como reducionistas, pois essas atividades de educação em saúde estão voltadas para ações de cunho prático, direcionadas a um fazer, relacionada à imposição e à instrução para sua viabilização.

Concordamos com os autores que acreditam que esse meio de trabalhar a educação em saúde com jovens "apresenta um enfoque dogmático que visa apenas uma mudança de comportamento do sujeito, [...] não promoverá uma tomada de consciência no sujeito, será uma ação mecânica, automatizada” (p. 6), ou seja, estes dois trabalhos mencionados acima não colocam a escola como detentora do saber, capaz de impor normas para que o aluno as sigam e garanta a sua saúde. Eles tratam a infância e a adolescência como sendo os períodos mais marcantes, intensos e mais plásticos no desenvolvimento de suas personalidades, sendo a escola um dos mecanismos mais importantes para promover saúde, no momento em que auxilie na construção de sua reflexão, possibilitando a construção do sujeito, levando-o a compreensão e a tomada de decisões autônomas em relação à saúde.

No trabalho de Monteiro, Vargas e Rebello (2003), estas autoras criticam a visão da promoção da saúde como estando atrelada a mudanças comportamentais, visto que esta se relaciona em normas e padrões adequadas de higiene, mudanças de hábitos e atitudes. O trabalho "valoriza a dimensão sociocultural e política do 
processo educativo, destacando as experiências e opiniões dos educandos" (p. 662). Os autores acreditam que o jogo procura incorporar uma visão crítica da educação no campo da saúde; tratam da educação em saúde como práticas sociais, estabelecidas entre profissionais de saúde, as instituições e os usuários das atividades no serviço de saúde, no qual é determinada tanto histórica, como social. Essa abordagem crítica, "valoriza o processo de capacitação dos indivíduos e de grupos para a transformação da realidade, em substituição à persuasão sobre os riscos de doença e agravo à saúde ou à transferência de informação" (p. 662).

O mesmo é possível observar no trabalho de Beserra et al. (2011), em que as autoras abordam que a educação em saúde visa contemplar os princípios do SUS por intermédio da promoção da saúde e da conscientização do indivíduo e da comunidade pelos seus direitos. Dessa forma, a articulação de meios que correlacionem educação em saúde, a fim de proporcionar mudança de comportamento do indivíduo, favorece a isenção de riscos que o impossibilitem de viver saudavelmente. Porém, elas acreditam que essa mudança de comportamento deve estar atrelada não à imposição de hábitos saudáveis, mas um aprendizado "contextualizado à realidade dos educandos, existindo uma inter-relação que proporciona liberdade e crítica acerca do assunto abordado." Ou seja, uma educação em saúde que permita incentivar os jovens, por meio do diálogo para uma reflexão crítica de sua realidade.

No trabalho de Blasca et al. (2013), que trata da capacitação de jovens estudantes do ensino médio, em um projeto denominado de "Projeto Jovem Doutor Bauru" que é uma estratégia educativa voltada para a prevenção de doença auditiva e promoção da saúde, as autoras acreditam que o projeto tem características peculiares que fundamentam a formação da aprendizagem colaborativa, proporcionando "a mudança de comportamento quanto aos aspectos relacionados à saúde" (p. 2). Porém, não tratam a respeito do pensamento crítico dos jovens com relação às suas próprias condições de saúde.

Esses trabalhos analisados nos levam a pensar sobre as limitações que ainda existem em relação ao tratamento das questões relacionadas à saúde no contexto escolar. Ainda que o campo da saúde já tenha avançado nas discussões acerca do autocuidado, da promoção da saúde e dos determinantes sociais da saúde, no âmbito escolar, ainda prevalece uma visão comportamentalista sobre a saúde. 


\section{CONCLUSÕES}

Diante dos resultados encontrados, podemos traçar um perfil da produção com as seguintes características: foco nas instituições escolares, predominância de investigar os alunos, visando mudança de comportamentos, numa concepção de educação mais tradicional. As pesquisas tiveram enfoques mais qualitativos, sejam para os estudos empíricos ou para os teóricos.

Esses aspectos nos levam a considerar que a área de educação em saúde, e também a educação em saúde atrelada aos jovens ainda não conseguiu avançar para uma abordagem tomada como processo social, propondo ir além das práticas educativas restritas a indivíduos, grupos ou populações. Com isso, pensamos que a educação em saúde ainda não é tomada como mediação de relações sociais com a totalidade (MELO, 1992), deixando de ser um mero processo de aquisição de conhecimentos para se tornar um processo de reflexão e questionamentos das condições de vida (FREIRE, 1970; MOHR; SCHALL, 1992) tendo como horizonte a transformação da sociedade.

Consideramos que a educação em saúde deve conferir privilégio aos espaços coletivos e a enfatizar a necessidade de se reconhecer o caráter histórico e os condicionantes sociais, políticos e econômicos do processo saúde/doença, propondo assim a formação de uma consciência crítica voltada à transformação da realidade social.

\section{REFERÊNCIAS}

ABRAMOVAY, M.; CASTRO, M.G.; SILVA, L.B. Juventude e sexualidade. Brasília: UNESCO, 2004

ADORNO, S. Exclusão socioeconômica e violência urbana. Sociologias, Porto Alegre, v. 4 , n. 8 , jul./dez. 2002, p. 84-135

ALVES, V. S. Um modelo de educação em saúde para o Programa Saúde da Família: pela integralidade da atenção e reorientação do modelo assistencial. Interface Comunic., Saúde, Educ., v. 9, n.16, p.39-52, fev. 2005

ANDRÉ, M.; ROMANOWSKI, J. O tema formação de professores nas dissertações e teses (1990-1996). In: FORMAÇÃO de professores no Brasil. Brasília: MEC/INEP/ 
COMPED, 2002, v.1, p. 17-156.

BESERRA, E. P.; TORRES, C.A.; PINHEIRO, P.N.C.; ALVES, M.D.S.; BARROSO, M.G.T. Pedagogia freireana como método de prevenção de doenças. Ciênc. saúde coletiva, v.16, suppl.1, p. 1563-1570, 2011.

BLASCA, W. Q.; PICOLINI, M.M.; SILVA, A.S.C; CAMPOS, K.; PINTO, G.F.R.; BRASOLOTTO, A.G.; ALVARENGA, K.F.; MAXIMINO, L.P; BERRETIN-FLEIX, G. Projeto Jovem Doutor Bauru: capacitação de estudantes do ensino médio em saúde auditiva. Rev. CEFAC., v. 15, n. 6, p. 1407-1417, 2013.

BRASIL. Ministério da Saúde. As causas sociais das iniquidades em Saúde no Brasil: Relatório Final da Comissão Nacional dos Determinantes Sociais em Saúde. Brasília, DF: Ministério da Saúde, 2009.

BRASIL. Ministério da Saúde. Caderno do gestor do PSE. Ministério da Saúde, Ministério da Educação. Brasília: Ministério da Saúde, 2015. 68p.

BRASIL. Ministério da Saúde. Secretaria de Vigilância em Saúde. Política Nacional de Promoção da Saúde. Ministério da Saúde, Secretaria de Atenção à Saúde. Brasília: Ministério da Saúde, 2006. 60p. (Série B. Textos Básicos de Saúde).

CARRANO, P.C.R.; MARTINS, C.H. S. A escola diante das culturas juvenis: reconhecer para dialogar. Educação, Santa Maria, v. 36, n. 1, p. 43-56, jan./abr. 2011.

CARVALHO, G.S.; GONÇALVES, A. Efeito da escolarização na convergência de modelos e de comportamentos de saúde em jovens estudantes portugueses de meio rural e meio urbano. In: ENCONTRO NACIONAL DE PESQUISA EM EDUCAÇÃO EM CIÊNCIAS, 8., 2011; CONGRESSO IBEROAMERICANO DE INVESTIGACIÓN EN ENSEÑANZA DE LAS CIÉNCIAS, 1., 2012. Anais... Campinas: UNICAMP, Brasil, 2011, p. 1-15.

CASTRO, M. G. Emancipação, cidadania e juventudes: estes tempos. Rio de Janeiro: FLACSO Brasil, 2014. (Serie Cadernos FLACSO).

CASEMIRO, J. P., FONSECA, A. B. C. Da, SECCO, F. V. M. Promover saúde na escola: reflexões a partir de uma revisão sobre saúde escolar na América Latina. Ciênc. saúde coletiva, Rio de Janeiro, v. 19, n. 3, p. 829-840, Mar. 2014.

COSTA, S., ZANCUL M. S. Educação alimentar em uma instituição total. In: ENCONTRO NACIONAL DE PESQUISA EM EDUCAÇÃO EM CIÊNCIAS - ENPEC, 9., 
2013, Águas de Lindóia, Anais... Águas de Lindóia: ABRAPEC, 2013.

COSTA, F. S.; SILVA, J.L.L.; DINIZ, M.I.G. A importância da interface educação/saúde no ambiente escolar como prática de promoção da saúde. Informe-se em promoção da saúde, v.4, n. 2. p. 30-33, 2008.

FERREIRA, N. As pesquisas denominadas "Estado da Arte". Educação e Sociedade, v. 23, n. 79, ago. 2002.

FICO, C. Versões e controvérsias sobre 1964 e a ditadura militar. Rev. Bras. Hist., v. 24, n. 47, p. 29-60, 2004.

FREIRE, P. Educação como prática da liberdade. 25. ed. São Paulo: Paz e Terra, 2001.

FREIRE, P. Pedagogía da autonomia: saberes necessários à prática educativa. 14 . ed. Rio de Janeiro: Paz e Terra, 1997.

FREIRE, P. Pedagogia do oprimido. 17 ed. Rio de Janeiro, Paz e Terra, 1987.

FREIRE, P. Pedagogia do oprimido. 36. ed. Rio de Janeiro: Paz e Terra, 1970.

FRIGOTTO, G. A produtividade da escola improdutiva. São Paulo, Cortez, 1999.

GAZZINELLI, M. F.; GAZZINELLI, A.; REIS, D. C.; PENNA, C. M. M. Educação em saúde: conhecimentos, representações sociais e experiências da doença, Cadernos de Saúde Pública, Rio de Janeiro, v.21, n.1, p. 200-206, 2005.

GOMES, J. As escolas promotoras de saúde: uma via para promover a saúde e a educação para a saúde da comunidade escolar. Revista Educação, Porto Alegre, v. 32, n. 1, p. 84-91, 2009.

GONÇALVEZ, M. G. M. Concepções de adolescência veiculadas pela mídia televisiva: um estudo das produções dirigidas aos jovens. In: OZELLA, S. Adolescências construídas: a visão da psicologia sócio-histórica. São Paulo: Cortez, 2003.

ILHA, P. V.; LIMA, A.P.S.; ROSSI, D.S.; WOLLMANN, E.M.; KRUG, M.R.; SOARES, F.A.A. A transversalidade do tema promoção da saúde nas disciplinas escolares. In: ENCONTRO NACIONAL DE PESQUISA EM EDUCAÇÃO EM CIÊNCIAS - ENPEC, 9., 2013, Águas de Lindóia. Anais... Águas de Lindóia, SP: ABRAPEC, 2013.

KAHHALE, E. M. S. P. Gravidez na adolescência: orientação materna no pré-natal. In: OZELLA, S. (Org.). Adolescências construídas: a visão da psicologia sócio- 
histórica. São Paulo: Cortez, 2003.

LANES, K. G.; LANES, D.V.C.; PUNTEL, R.L.; FOLMER, V. Alternativas interdisciplinares para a Promoção de Saúde do Escolar. In: ENCONTRO NACIONAL DE PESQUISA EM EDUCAÇÃO EM CIÊNCIAS - ENPEC, 9., 2013, Águas de Lindóia. Anais... Águas de Lindóia, SP: ABRAPEC, 2013.

LANES, K. G.; LANES, D.V.C.; PUNTEL, R.L.; SOARES, F.A.A.; FOLMER, V. Alternativas pedagógicas associadas ao sobrepeso e obesidade em escolares. In: ENCONTRO NACIONAL DE PESQUISA EM EDUCAÇÃO EM CIÊNCIAS, 8., 2012; CONGRESSO IBEROAMERICANO DE INVESTIGACIÓN EN ENSEÑANZA DE LAS CIÉNCIAS, 1. 2012. Anais... Campinas: ABRAPEC, 2011, p. 1-15.

LIBÂNEO, J. C. Tendências pedagógicas na prática escolar. Revista da Associação Nacional de Educação, v.3, p.11-19, 1983.

LIBERAL, E. F. et al. Acidentes e danos com escolares: incidência, causas e consequências Jornal de Pediatria, v. 81, n.5 (supl), p. 155-163, 2005.

LOUREIRO, S. A questão do social na epidemiologia e controle da esquistossomose mansonica. Memórias do Instituto Oswaldo Cruz, v. 84, supl. I, p. 124-133, 1989.

MARINHO, J. C. B.; SILVA, J. A. Implicações de atividades que priorizam o fazer para a concretização da educação em saúde. In: ENCONTRO NACIONAL DE PESQUISA EM EDUCAÇÃO EM CIÊNCIAS - ENPEC, 9., 2013, Águas de Lindóia. Anais... Águas de Lindóia, SP: ABRAPEC, 2013.

MELO, J. A. Educação e as práticas de saúde. In: MALHÃO, A.; BRASIL, I.; MUNCK, S. (Org.). Trabalho, educação em saúde: reflexões críticas de Joaquim Alberto Cardoso de Melo. Rio de Janeiro: EPSJV, 2007.

MELO, J. A. Educação em saúde: dimensões da vida e da existência humana. In: AMÂNCIO FILHO, A. (Org.). Saúde, trabalho e formação profissional. Rio de Janeiro: FIOCRUZ, 1992. p. 65-69.

MESSINA, G. Estúdio sobre el estado del arte de la investigación acerca de la formación docente en los noventa. México: Mimeo, 1998.

MOHR, A.; SCHALL, V. Rumos da educação em saúde no Brasil e sua relação com a educação ambiental. Cadernos de Saúde Pública, Rio de Janeiro, v. 8, n. 2, abr./ jun. p. 199-203, 1992. 
MONTEIRO, S. S.; VARGAS, E. P.; REBELLO, S. M. Educação, prevenção e drogas: resultados e desdobramentos da avaliação de um jogo educativo. Educ. Soc. v. 24, n. 83, p. 659-678, 2003.

ROCHA, E.C. A pesquisa em educação infantil no Brasil: trajetória recente e perspectiva de consolidação de uma pedagogia. Florianópolis: UFSC, Centro de Ciências da Educação, Núcleo de Publicações, 1999.

SAVAGE, J. A criação da juventude: como o conceito de teenage revolucionou o século XX. Rio de Janeiro: Rocco, 2009.

SILVA, J. R. C.; SEVERO, T.E.A.; DIAS, M.A.S. Estudos das expressões míticas acerca da prevenção das doenças parasitárias: Novas possibilidades para o Ensino de Biologia. In: ENCONTRO NACIONAL DE PESQUISA EM EDUCAÇÃO EM CIÊNCIAS, 8., 2012; CONGRESSO IBEROAMERICANO DE INVESTIGACIÓN EN ENSEÑANZA DE LAS CIÉNCIAS, 1., 2012. Anais... Campinas: ABRAPEC, 2011.

SILVA, M.; HAYASHI, C.; HAYASHI, M. Análise bibliométrica e cientométrica: desafios para especialistas que atuam no campo. InCID: Revista de Ciência da Informação e Documentação, v. 2, n. 1, p. 110-129, 2011.

STOTZ, E. N. Participação popular, educação em saúde: teoria e prática. Rio de Janeiro: Relume-Dumará, 1993.

VASCONCELOS, E. M. Atenção primária à saúde e o cotidiano das doenças infecciosas e parasitárias no meio popular. In: EDUCAÇÃO popular e a atenção à saúde da família. 2. ed. São Paulo/Sobral: HUCITEC/UVA, p. 11-20, 2001.

VENTURI, T.; MOHR, A. Análise da educação em saúde em publicações da área de Educação em Ciências. In: In: ENCONTRO NACIONAL DE PESQUISA EM EDUCAÇÃO EM CIÊNCIAS, 8., 2012; CONGRESSO IBEROAMERICANO DE INVESTIGACIÓN EN ENSEÑANZA DE LAS CIÉNCIAS, 1., 2012. Anais... Campinas: ABRAPEC, 2011.

VERMELHO, S.C, AREU, G.I. Estado da arte da área de Educação \& Comunicação em periódicos brasileiros. Educação e Sociedade, v.26, p. 1413-1434, 2005.

Recebido em: 02 de marco de 2017 Aceito em: 31 de maio de 2017 